\title{
ПСИХОЛОГИЧЕСКИЕ HАУКИ
}

УДК 612.821-615.832.9:616.127

\section{ON VALUE OF THE PSECHOLOGICAL SELF-REGULATION METHODS WITHIN COMPLEX THERAPY FOR CHRONIC PAIN PATIENTS}

DOI: 10.31618/ESU.2413-9335.2019.7.66.330

Ishinova $V$. A.

PhD, medical psychologist,

Department of Psychological Rehabilitation,

FSBA «Federal Scientific Disabled Rehabilitation Center

named after G.A. Albrecht,

St. Petersburg

Davidov A. T.

Doctor of Medical Sciences,

Professor, psychiatrist,

FSBA «Federal Scientific Disabled Rehabilitation Center

named after G.A. Albrecht,

St. Petersburg

\section{SUMMARY}

The article presents the research results of psychophysiological state of patients with musculoskeletal diseases suffering from chronic pain who received the complex treatment. The method of "Empatho-techique" was used to eliminate chronic pain for one of the patients' groups. Objective of research: to investigate the change of psychophysiological state of the patients with diseases of musculoskeletal system suffering from chronic pain at the beginning and at the end of complex therapy course with or without Empatho-technique used. The outcome revealed significant decrease of chronic pain intensity and improvement of their psychophysiological state. The received data confirm the leading chronic pain role in changing of psychophysiological patients' state and underline the necessity of including the drug-free methods in complex treatment programs. It is also of utmost importance to actively involve medical psychologists and psychotherapists in developing new effective chronic pain treatment methods.

Key words: Empatho-technique, emotional and personal characteristics, Autogenic training, Tropho-tropic activity, Ergo-tropic activity, vegetative coefficient, non-drug methods, multidisciplinary medical center.

\section{Introduction}

Psychological factors are known to play an important role in development of various diseases [2, 9, 21]. Thus, there are no doubts in the interactions between the components of the negative triad (anxiety, hostility, depression) and the development of such diseases as the ischemic heart disease, the bronchial asthma, the diseases of the musculoskeletal system [16, 21]. Furthermore, as investigation results have shown, the psychological factors turned out to be of more significance than the classic risk factors hypercholesterolemia, harmful habits, hypodynamia. At the same time with the increase of somatic burden and formation of chronic pain syndrome, the decrease of adaptive possibilities of the body and development of the cognitive and affective disorders are observed [2, $16,17]$. At this, over time, the chronic pain (CP) becomes an independent disease and can continue for very long time, lead to reduction of physical activity and to disability, despite the elimination of its occurrence causes [12, 16, 19].

The high CP prevalence in the clinical practice and low effectiveness of symptomatic treatment are a powerful incentive for working out the new effective CP treatment methods which take into account the multicomponent structure [10, 11, 14].

Namely therefore, it is necessary to use the complex approach including not only medicament therapy, physiotherapy procedures but also psychotherapy methods of impacting the emotional and personal spheres, behavioral responses of patients suffering from $\mathrm{CP}$. We consider the introduction of non-invasive methods for $\mathrm{CP}$ elimination in the complex treatment program to be crucial $[8,12,15]$.

In this article, there are submitted the outcomes of the investigation of psychophysiological state change of patients suffering from $\mathrm{CP}$ who underwent the complex therapy course where the psychophysiological self-regulation method (Empatho-technique) was used for one of groups.

Objective of research: to investigate the change of psychophysiological state of the patients with diseases of musculoskeletal system suffering from chronic pain at the beginning and at the end of complex therapy course with or without Empatho-technique used.

The following tasks were set:

- to set groups of patients with musculoskeletal system diseases suffering from chronic pain;

- to perform the psycho-diagnostic investigation at the beginning and at the end of the treatment period;

- to use the Autogenic training course as a psychotherapy method to improve the emotional state and healthy sleep; 
- to apply Empatho-techique to diminish $\mathrm{CP}$ level in one group of the patients;

- to conduct statistical analysis of the results obtained.

- to draw conclusions based on the obtained results.

\section{Materials and methods}

There were investigated 83 patients with diseases of musculoskeletal system (DMS) suffering from CP. They underwent the course of the treatment in Clinic of FSBA «Federal Scientific Disabled Rehabilitation Center named after G.A. Albrecht».

Participants

- Group 1 included 47 patients (23 males and 24 females aged 47 to 69 ). In the investigated group $41 \%$ patients were diagnosed (according to MCD-10) with "Spinal osteochondrosis in adults" (M42.1); 20\% "Other polyarthrosis" (M 15.8); 18\% - "Primary generalized (osteo) arthrosis" (M15.0); 9\% - "Primary bilateral coxarthrosis" (M16.0); 1\% - "Other specified arthritis" (M13.8); 5\% - "Joint contracture" (M24.5); $6 \%$ - "Primary arthrosis of other joints" (M19.0). Most patients $(81 \%)$ arrived in the hospital from different Russian Federation regions, 19\% - were residents of Saint-Petersburg.

- Group 2 consisted of 36 patients (8 males and 27 females aged 63 to 72). They were diagnosed with: "Spinal osteochondrosis in adults" (M42.1) - $64 \%$ patients; 7\% - "Joint contracture" (M24.5); 12\% "Other polyarthrosis" (M 15.8); 8\% - "Primary bilateral coxarthrosis" (M16.0); 9\% - "Primary arthrosis of other joints" (M19.0). All patients of this group were St. Petersburg residents.

The patients' complaints contained predominantly the pain syndromes in their joints and spine, as well as complaints of sleep disorders, unstable mood, rapid fatigability, anxiety, decrease of physical activity and working capacity.

Both groups were obtaining a complex therapy including drug and physiotherapy procedures, as well as therapeutic physical training. The course of group Autogenic Training (using Audio-visual complex "Disnet-2") was prescribed to improve the psychological and physiological state of patients and to eliminate their sleep disorders [1].

"Empatho-techique" was used for CP decrease only in patients of Group 1.

Psychodiagnostic investigation was performed at the beginning and at the end of the treatment course [4, $5,6,7]$.

The psycho-emotional state, the personality characteristics of the patients, sleep disturbance and the severity of the vegetative manifestations of the cardiovascular and respiratory systems were determined using Questionnaire "Symptom Check List SCL-90-R" according to scales: anxiety (ANX), depression (DEP), interpersonal sensitivity (INT), hostility (HOS), sleep and eating disorder (ADD), phobic anxiety (PHOB), somatization (SOM), global severity index (GSI) [20].

To determine the vegetative coefficient (VC) level we used the eight-color Lusher test. The level from 0,2 to 0,49 was characterized by the presence of asthenia signs (trophotropic activity (TTA) dominating); from 0,50 to 0,94 - optimal level of TTA with adequate energetic potential for successful activity; from 0,95 to 1,39 - optimal level of ergotropic activity (ETA); above 1,40 - hyperexcitability (ETA dominating). [18]

Visual analogical scale (VAS) was used for assessment of CP intensity at the beginning and at the end of Complex therapy course. VAS is a horizontal line where figures from 0 to 10 are dimentioned this way: 0-1- no pain or the condition of the light discomfort; from 1,1 to 3,0 - light pain; from 3,1 to 5,0 - the moderate level of the pain intensity; from 5,1 to 7,0 - strong pain; from 7,1 to 9,0 - very strong pain; from 9,1 to 10,0 - unbearable pain [3].

Statistical processing of the obtained data was carried out using the STATISTICA 12.0 program for parametric and non-parametric parameters.

Results and discussion. In both group of patients with strong CP (Gr. $1=6,68 \pm 0,30$; Gr. $2=5,42 \pm 0,31)$ the high levels of ANX and DEP were registered. These indices had no differences between groups. But substantially higher $(p<0,001)$ level of HOS was revealed in patients of Group 1 in comparison with that of Group 2 patients (Table 1).

Table 1

DESCRIPTIVE STATISICS. AVERAGE MEASURES OF THE EMOTIONAL AND PERSONAL CHARACTERISTICS WITH USING QUESTIONNAIRE "SYMPTOM CHECK LIST SCL-90-R" IN PATIENTS SUFFERING FROM CHRONIC PAIN

\begin{tabular}{|c|c|c|c|c|c|}
\hline \multirow[b]{2}{*}{ Questionnaire } & \multirow[b]{2}{*}{ Scales } & \multicolumn{2}{|c|}{ Group 1} & \multicolumn{2}{|c|}{ Group 2} \\
\hline & & $\begin{array}{l}\text { Before } \\
\mathrm{M} \pm \text { SE }\end{array}$ & $\begin{array}{c}\text { After } \\
\mathrm{M} \pm \mathrm{SE}\end{array}$ & $\begin{array}{l}\text { Before } \\
\mathrm{M} \pm \text { SE }\end{array}$ & $\begin{array}{c}\text { After } \\
\mathrm{M} \pm \mathrm{SE}\end{array}$ \\
\hline \multirow{7}{*}{ 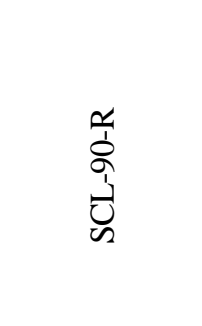 } & ANX & $0,86 \pm 0,09$ & $0,48 \pm 0,06$ & $0,68 \pm 0,12$ & $0,52 \pm 0,10$ \\
\hline & DEP & $0,90 \pm 0,11$ & $0,52 \pm 0,05$ & $0,87 \pm 0,13$ & $0,57 \pm 0,09$ \\
\hline & INT & $0,97 \pm 0,11$ & $0,56 \pm 0,06$ & $0,89 \pm 0,14$ & $0,61 \pm 0,10$ \\
\hline & $\mathrm{HOS}$ & $0,93 \pm 0,12$ & $0,45 \pm 0,06$ & $0,52 \pm 0,08$ & $0,38 \pm 0,05$ \\
\hline & SOM & $1,08 \pm 0,13$ & $0,61 \pm 0,07$ & $1,21 \pm 0,13$ & $0,92 \pm 0,14$ \\
\hline & ADD & $1,13 \pm 0,10$ & $0,57 \pm 0,05$ & $0,83 \pm 0,13$ & $0,68 \pm 0,12$ \\
\hline & GSI & $0,82 \pm 0,09$ & $0,56 \pm 0,04$ & $0,78 \pm 0,10$ & $0,57 \pm 0,08$ \\
\hline
\end{tabular}

$\mathrm{M} \pm \mathrm{SE}$ - Mean \pm Standard Error of mean; SOM - somatization; ANX - anxiety; DEP - depression; HOS - hostility; INT - interpersonal sensitivity; ADD - sleep and eating disorder; GSI - symptom severity index. 
The high levels of ADD and SOM in both groups indicated sleep disturbance signs and the expressed vegetative manifestations of the cardiovascular, respiratory systems as well as gastrointestinal tract. Patients complained about experienced giddiness, the heart or chest pain, the heartbeat, the nausea or indigestion, the breathing difficulty, the lump in the throat, the tingling sensations in different parts of the body, etc. The increased GSI indices which reflect the disease severity had no valid differences in both groups.

Also there were found out significant fluctuations of VC in both groups of patients, from asthenia to signs of increased excitability. However, the asthenia state which manifested itself in the form of rapid fatigability, reduced vitality, and the state of nervousness was revealed in group 1 patients more expressedly than in group 2. In contrast to patients of group 1 where the optimal levels of the Trophotropic and Ergotropic activity of middle range were equal, patients of group 2

demonstrated the predominance of the optimal Ergotropic activity level (Table 2).

At the end of the complex therapy course which included Empatho-technique, the level of CP intensity significantly $(p<0.01)$ decreased, and patients of Gr.1 were perceiving it as the discomfort state. Also, the reduction of ANX, DEP, HOS levels and the vegetative manifestations of the basic bodily systems were registered.

In patients of Gr.2, who didn't undergo the Empatho-technique course, the CP intensity decreased to the moderate level $(4,03 \pm 0,24)$ only. It was accompanied by the slight decrease in the ANX, HOS, SOM levels and insignificant improvement in sleep. At the same time, in patients of Gr.2 there were observed improved DEP and INT indices which told on the mood improvement and communicative activity.

Furthermore, the levels of GSI improved insignificantly in both groups (Table 1).

Table 2

THE VEGETATIVE COEFFICIENT (VC) LEVELS IN PATIENTS SUFFERING FROM CHRONIC PAIN BEFORE AND AFTER COURSE OF THE TREATMENT

\begin{tabular}{|c|c|c|c|c|c|}
\hline \multirow{6}{*}{ 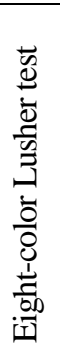 } & \multirow{2}{*}{$\begin{array}{l}\text { The levels of the } \\
\text { Vegetative coefficient }\end{array}$} & \multicolumn{2}{|c|}{ Group 1} & \multicolumn{2}{|c|}{ Group 2} \\
\hline & & Before & After & Before & After \\
\hline & $\begin{array}{c}\text { Asthenization } \\
\text { (TTA dominating) }\end{array}$ & $17,0 \%$ & $4,3 \%$ & $9,2 \%$ & $9,1 \%$ \\
\hline & optimal level of TTA & $29,8 \%$ & $57,4 \%$, & $18,2 \%$ & $40,9 \%$, \\
\hline & optimal level of ETA & $27,6 \%$ & $36,2 \%$. & $54,54 \%$, & $36,4 \%$. \\
\hline & $\begin{array}{l}\text { Hyperexcitability } \\
\text { (ETA dominating) }\end{array}$ & $25,6 \%$ & $3,1 \%$ & $18,2 \%$ & $13,6 \%$ \\
\hline
\end{tabular}

With the reduction in pain intensity and improvement of the psycho-emotional state in patients of group 1, the change of VC fluctuations was observed: the patients number with asthenia and hyperexcitability signs decreased substantially (the number of similar patients in Group 2, correspondingly, did not change or changed insignificantly); the number of patients with optimal Tropho-tropic activity level increased $(p<0,001)$ in both groups; The number of patients with optimal Ergo-tropic activity in Group 1 became a bit more numerous (their number has reduced insignificantly in Group 2 in contrast to that at the beginning of complex therapy course). (Table 2)

Conclusions and suggestions. Thus, at the beginning of the complex therapy the strong $\mathrm{CP}$ was accompanied by the emotional and personal disturbances, the sleep disorder and the pronounced vegetative manifestations of the bodily basic systems. The social factors (bureaucratic paperwork and financial constraints) could serve as the main reason of the higher negative emotion levels and the sleep disorder in patients of Group 1 in comparison with their counterparts of Group 2. Besides, whereas the main reason for hospitalization of Group 1 patients was the strong CP in their medical history, the key cause of hospital admission for patients of Group 2 (all St.Petersburg's residents), was the improvement of communication skills and social adaptation
It can be assumed that the more significant improvement of the practically all indices in Group 1 patients at the end of the complex therapy course could be related to the $\mathrm{CP}$ decreased intensity. In contrast to that, the CP intensity in Group 2 patients stayed on the same level which could be explained by the lack of substantial changes in their psychophysiological state.

The obtained results highlight the defining role of $\mathrm{CP}$ in the change of psychophysiological state of patients, which emphasizes the necessity of including the non-invasive methods in the CP patients' treatment program. It is also of utmost importance to actively involve medical psychologists and psychotherapists in developing new effective CP treatment methods.

\section{References}

1. Audiovisual complex "Disnet-2". User's Guide. Moscow. 2007; Company "Disnet" www.disnet.ru ver. 1.1.07.06:23;

2. Denisov I.N., Kandyba D.V., Kuznetsova O.Yu. Chronic back pain. //Clinical guidelines. Moscow-Saint-Petersburg-Rostov-on-Don. 2014; 20;

3. Hawker G.A., Mian S., Kendzerska T., French M. Measures of adult pain: Visual Analog Scale for pain (VAS Pain), Numeric Rating Scale for Pain (NRS pain), McGill Pain Questionnaire (MPQ), Short-Form McGill Pain Questionnaire (SF-MPQ), Chronic Pain Grade Scale (CPGS), Short Form-36 Bodily Pain Scale 
(SF-36 BPS), and Measure of Intermittent and Constant Osteoarthritis Pain (ICOAP). Arthritis Care Res. 2011; 63(11): 240-52. Doi:10.1002/acr.20543;

4. Ishinova V.A, Svyatogor I.A., Reznikova T.N. Features of color reflection in psychogenic pain in patients with somatoform disorders during psychotherapeutic treatment //The Spanish Journal of Psychology. 2009; 12:2:715-724;

5. Ishinova V.A., Svyatogor I.A. Comparative evaluation of effectiveness of self-regulation methods based on the external and internal feedback systems //Sbornik materialov IX Mezdunarodnoj nauchnoj conferencii "Potencial lichnosti: kompleksnaja problema". Tambov. 2010:272 - 279;

6. Ishinova V.A., Ishinov I. U. Features of using of empatho-technique

for patients with phantom pain //Psychopathology and Addiction Medicine 1.2. 2016: 17-25;

7. Ishinova V. A., Mitjakova O.N., Povorinskij A.A., Serdjukov S. V. Features of the proportions of psychogenic and somatogenic components in the structure of chronic pain (on the example of coronary heart disease and somatoform disorders //Zhurnal «Mediko-social'naja jekspertiza i reabilitacija». 2017; 1:9-14;

8. Kargaltsev A.A., Makarov M.A. Pain in the lumbar spine: etiology, differential diagnosis and treatment (literature review and clinical case). Neuromuscular Diseases. 2018; 8(4):61-70. https://doi.org/10.17650/2222-8721-2018-8-4-61-70;

9. Kryzhanovskij G.N. Central mechanisms of pathological pain //Journal of neurology and psychiatrie named after C.C. Korsakov. 1999; 99:4-7;

10. Kudyashev A.L., Khominets V.V., Shapovalov V.M., Miroevsky F.V. Coxovertebral syndrome in the complex treatment of patients with a combination of degenerative-dystrophic pathology of the hip joint and spine. //Bulletin of Traumatology and Orthopedics named after N.N. Pirogov. 2015; 2: 76-82;

11. Kukushkin MD Ethiopathogenetic principles of chronic pain treatment // Russian Medical Journal. 2007; 15:827-835;
12. Nicholas J.M., Jillian P.E., David J.H. Hip osteoarthritis: etiopathogenesis and implications for management. Adv Ther 2016;33:1921-46. PMID:27671326;

13. Salazar A., Duenas M., Mico J. A., Ojeda B., Aguera-Ortiz L., Cervilla J. A. \& Failde I. Undiagnosed mood disorders and sleep disturbance in primary care patients with chronic muscuoskeletal pain //Pain Medicine. 2013; 14:1416-1425;

14. Sergeev A.V. Lower back pain: evidencebased therapy and new opportunities //Neurology, neuropsychiatry, psychosomatics 2013; (3): 78-85. https://doi.org/10.14412/2074-2711-2013-2346;

15. Sharan, Ashwini, MD, FACS; Riley, Jonathan, MD; Hoelscher, Christian, MD Overview of Chronic Spinal Pain: Revisiting Diagnostic Categories and Exploring an Evolving Role for Neurostimulation //Spine. 2017; 15(42) Suppl 14:35-40.

16. Simanenkov V.I., Psychosomatic disorders in the therapist practice //Guidelines for physicians under editorship of Simanenkov I.V. St. Petersburg:SpecLit, 2008; 335;

17. Smart K.M., Blake C., Staines A. et al. Mechanisms-based classifications of musculoskeletal pain: part 1 of 3: symptoms and signs of central sensitization in patients with low back (+/- leg) pain. Man Ther 2012;17(4):336-44. PMID:22534654;

18. Sobchik L.N. (2001) Modified eight-color Luscher test. Practical guidelines. - SPb., Izd-vo «Rech», 2001;112;

19. Stanley J Antolak; David M Hough; Wojciech Pawlina; Robert J Spinner (2002) Anatomical basis of chronic pelvic pain syndrome: the ischial spine and pudendal nerve entrapment // Medical Hypotheses. 2002; 59(3):349-353;

20. Tarabrina N.V. Practicum in Post-traumatic Stress Psychology. SPb: Peter. 2001; 272;

21. Turner-Cobb J. M., Michalaki M., Osborn M. (2015); Self-conscious emotions in patients suffering from chronic musculoskeletal pain: A brief report // Psychology \& Health. 2015; 30:495-501.

Conflict of Interest: we have no conflict of interest. 